\title{
Evaluating a new verbal working memory-balance program: a double-blind, randomized controlled trial study on Iranian children with dyslexia
}

\author{
Mehdi Ramezani ${ }^{1}$, Saeed Behzadipour ${ }^{2,3}$, Ehsan Pourghayoomi ${ }^{1}$, Mohammad Taghi Joghataei ${ }^{1,4}$, \\ Elham Shirazi ${ }^{5^{*}}$ and Angela J. Fawcett ${ }^{6}$
}

\begin{abstract}
Background: It is important to improve verbal Working Memory (WM) in reading disability, as it is a key factor in learning. There are commercial verbal WM training programs, which have some short-term effects only on the verbal WM capacity, not reading. However, because of some weaknesses in current verbal WM training programs, researchers suggested designing and developing newly structured programs that particularly target educational functions such as reading skills. In the current double-blind randomized clinical trial study, we designed a new Verbal Working Memory-Balance (VWM-B) program which was carried out using a portable robotic device. The short-term effects of the VWM-B program, on verbal WM capacity, reading skills, and postural control were investigated in Iranian children with developmental dyslexia.
\end{abstract}

Results: The effectiveness of the VWM-B program was compared with the VWM-program as a traditional verbal WM training. In comparison with VWM-program, the participants who received training by the VWM-B program showed superior performance on verbal WM capacity, reading skills, and postural control after a short-term intervention.

Conclusions: We proposed that the automatized postural control resulting from VWM-B training had a positive impact on improving verbal WM capacity and reading ability. Based on the critical role of the cerebellum in automatizing skills, our findings support the cerebellar deficit theory in dyslexia.

Trial registration: This trial was (retrospectively) registered on 8 February 2018 with the Iranian Registry of Clinical Trials (IRCT20171219037953N1).

Keywords: Dyslexia, Working memory, Balance, Postural control, Cerebellum, Cognitive training, Computer assisted learning

*Correspondence: shirazi.e@iums.ac.ir

${ }^{5}$ Mental Health Research Center, Tehran Institute of Psychiatry, Iran

University of Medical Sciences, Tehran, Iran

Full list of author information is available at the end of the article

\section{Background}

Developmental Dyslexia (DD) is characterized as a difficulty in learning to read accurately and fluently [1], despite adequate intelligence, conventional classroom experience, and sufficient socio-economic opportunities [2]. 5-17.5\% of children in different countries suffer from DD [3, 4]. As shown below, several theories and approaches have described DD. 
Many studies have supported that reading difficulties in children with DD are due to phonological deficits, explained by the phonological deficit theory $[1,5,6]$. This theory has suggested that children with DD have a specific impairment in the representation, storage, and retrieval of speech sounds (phonological awareness problems) [7]. The phonological awareness problems lead to difficulties in grapheme-phoneme decoding of the lexical items. Insufficient grapheme-phoneme decoding causes the slowing process and inadequate recognition of letters $[1,5]$, leading to problems in segmentation and blending. Impaired phonological representations also limit the formation of long-term phonological representations in restoring phonological (verbal) Working Memory (WM) traces [8]. Hence, children with DD usually have deficits in verbal WM in addition to problems in phonological awareness, grapheme-phoneme decoding and segmentation $[9,10]$. The verbal WM engages the phonological loop component of WM and involves the temporary maintenance and manipulation of auditory-verbal information via vocal/subvocal rehearsal [11]. Extensive evidence has confirmed the existence of the verbal WM deficit in children with DD as a fundamental problem $[9,12-22]$. The verbal WM deficit in these children may extend into adulthood and thereafter affect performance in all components of WM [23]. Therefore, sufficient improvement of the verbal WM capacity in children with DD is necessary [24-26].

The cerebellar deficit theory, supported by several studies, has concluded that insufficient integration of information due to mild neurobiological impairment in the cerebellum is responsible for deficits in DD [16, 27-29]. This theory has postulated that retarded or dysfunctional articulation due to a weak capacity to automatize would lead to deficient phonological representations and affect the learning of grapheme-phoneme decoding [7, 30, 31]. As mentioned above, the impaired phonological representations limit the formation of long-term phonological representations in restoring verbal WM traces [8]. Furthermore, research has confirmed the imperative role of the cerebellum in verbal WM [32]. Unlike other approaches, the cerebellar deficits theory emphasizes postural control and balance disorders in children with DD besides supporting phonological and verbal WM deficits [1, 9, 16, 27, 33]. Cerebellar insufficiency leads to difficulties in developing automatized skills [16]. Due to incomplete automaticity, balance-related problems become apparent while performing dual-tasks or more complex tasks [34]. In dual-tasks, children with DD are unable to consciously compensate for both the cognitive or motor aspects of dual-tasks [34]. Dual-task paradigm studies have shown both postural control $[27,33,35]$ and cognitive performance insufficiency $[27,33]$ in children with DD. The postural control and cognitive demands, therefore, interact with each other in a cognitive-motor dual-task $[27,33,35]$. There is evidence that dual-task interference decreases and may even disappear while performing a dual-task condition [36]. In other words, dual-task training can improve dual-task performance [37] and this forms the motivation for the current study. Also, a cognitive-motor dual-task training program is more efficient than a single-task program to improve cognitive or motor performances [38-41] (e.g., balance performance $[40,42])$. Hence, we have supposed that a training program with a dual-task condition could be more effective than a single-task program to develop the abilities in children with DD.

Numerous computerized programs including Cogmed (www.cogmed.com), Jungle Memory (www.junglememo ry.com), and Cognifit (www.cognifit.com) are currently used to improve the verbal WM capacity [43]. These programs are typically commercial, and several studies have taken place to examine their effectiveness [25, 43-47]. Some studies demonstrated the positive effects of these programs on reading ability [25, 44]. However, many researchers have confirmed the short-term effects of these programs only on the verbal WM capacity [43, 4548 ], and in comparison to the other programs, Cogmed has larger effects on the verbal WM capacity [43]. Moreover, the current programs suffer from some weaknesses. They were not designed to teach the verbal WM explicit strategies, such as vocal/subvocal rehearsal techniques [49], and designed as a single-task training program that leads to specific-to-practice learning effects [48]. Because of these weaknesses, researchers suggested designing and developing newly structured WM programs that particularly target educational functions such as reading skills $[43,47,50]$. It seems that designing a new effective verbal WM training program for children with DD should be adapted to cover difficulties in balance and automaticity.

The current study hypothesizes that a new dual-task program that involves explicit strategies of vocal/subvocal rehearsal and targets the reading skills and balancerelated performance simultaneously, would be more effective than the current programs to improve the verbal WM capacity, reading skills, or postural control. In essence, the research design compared the progress of dyslexic children who either experienced a WM battery (control group) or the same WM battery under dualtask balance conditions (intervention group) which are hypothesized to improve performance. In the present study, a dual-task, Verbal Working Memory-Balance (VWM-B) program, was designed and its short-term effects on verbal WM capacity, reading skills, and 
postural control were investigated in Iranian children with DD.

\section{Methods}

\section{Subjects and design}

This quasi double-blind randomized clinical trial study was performed with a between-subjects factor 'group' (control group vs. intervention group) and within-subjects factor 'time' (measurement at pre-intervention and post-intervention) and has adhered to CONSORT guidelines (Additional file 1: Appendix S1). Data collection started in March 2018 and ended in November 2018. First, an invitation letter was sent from the 'education office, District 20, Tehran, Iran' to the principals of the public elementary schools in this region for referring students with reading deficiency (Fig. 1). After the invitation, children with difficulties in learning to read, reported by their teachers or those with a previous diagnosis of DD, were participated in preliminary screening. Then, the word reading efficiency (WR) and non-word reading efficiency (NWR) subtests of the validated and reliable Persian battery of normative reading tests-NEMA [51] were used to confirm the existence of DD. Children who obtained a score of $25 \%$ or less for WR and NWR subtests in the preliminary screening were included in the study [51]. Non-words are particularly important in diagnosing dyslexia for those who follow the phonological deficit hypothesis [52]. It should be noted that Iranian children begin to learn to read at the age of 4-5 years when they participate in preschool classes [53]. Preschool is an informal education course in Iran (under the supervision of the education ministry), and mandatory (at least for 1 year) before receiving a formal education course [53]. Iranian children, older than 6 years, attend the first grade of elementary school and formally learn to read [53]. With this explanation, we have requested teachers to report their students who had learning problems to read after at least 6 months of education in the first-grade. Therefore, children in the first grade of the school should have received at least 18 months of education services. However, all first-grade participants in the present study had received more than 21 months of education services.

Inclusion criteria were normal IQ, normal attention, normal vision/hearing conditions, right-handed, nativePersian language, and average socio-economic status as reported by the families. The Wechsler Intelligence Scale for Children-Fourth Edition (WISC-IV) was used to test the IQ and subjects with a WISC-IV total score ${ }^{<} 85$ excluded from the study [54]. Also, the Persian version of the parent checklist of the Child Symptoms Inventory (CSI-4) was utilized to test attention (items 1 to 18 out of 97) $[55,56]$. Subjects with total scores of 1-18 items $\geq 7$ were excluded from the study [55-57]. Furthermore, none of the children had a history of neurological or psychiatric disorders and were taking no drugs affecting the central nervous system.

According to Fig. 1, which illustrates the procedure of recruiting participants in accordance with CONSORT guidelines [58], 36 children with DD were recruited to the study following formal diagnostic and behavioral pre-intervention assessments. However, with an approximate drop-out rate of $20 \%$, data collected from 29 subjects entered the statistical analysis. The current study sample size is consistent with similar previous studies [44, 59-61] and is supported by Julious et al. who suggested at least 12 subjects per group in trial studies [62]. The Block randomization method in a 1:1 ratio was performed, by a computer, to allocate participants into two groups [63]. Randomization was performed in blocks of six and a block size of four to ensure a balance in sample size across groups. Also, both groups were matched by age (years), height $(\mathrm{cm})$, weight $(\mathrm{kg})$, full-IQ score (tested by WISC-IV [54]), and attention (tested by CSI-4 [57]), as possible confounders.

For double-blinding in the current study, children and their parents were unaware of the group to which the children had been allocated. Also, an evaluator who was not a member of the research group blinded to the subjects' groups performed the pre-intervention and post-intervention behavioral assessments. Recording the Center of Pressure (CoP) data using a force plate (more details are given in Section "Assessments" in the "Methods") was performed on the same day with the behavioral measures. The analyzer of CoP data was also blinded to the allocated intervention. Despite blinding children/ parents and evaluator/analyzer to the allocated intervention and pre-intervention/post-intervention assessments, the participants would obviously recognize whether or not they had undertaken the training in the balance condition. Hence, the study design may be considered quasi double-blind.

Children were assessed individually at initial screening, pre-intervention, and post-intervention, separated by an average of 44 days. Outcomes of the diagnostic reading subtests, obtained from the initial screening, were used as the pre-intervention score for children who were recruited for the study. All participants in both groups completed 5 weeks, 3 days per week, one session per day, and 45-60 min per session intervention. Failing to complete a minimum of $75 \%$ of the training sessions, i.e., four out of 15 sessions, has been determined to exclude the participant's data from the statistical analysis (all subjects, however, participated in all 15 sessions). 


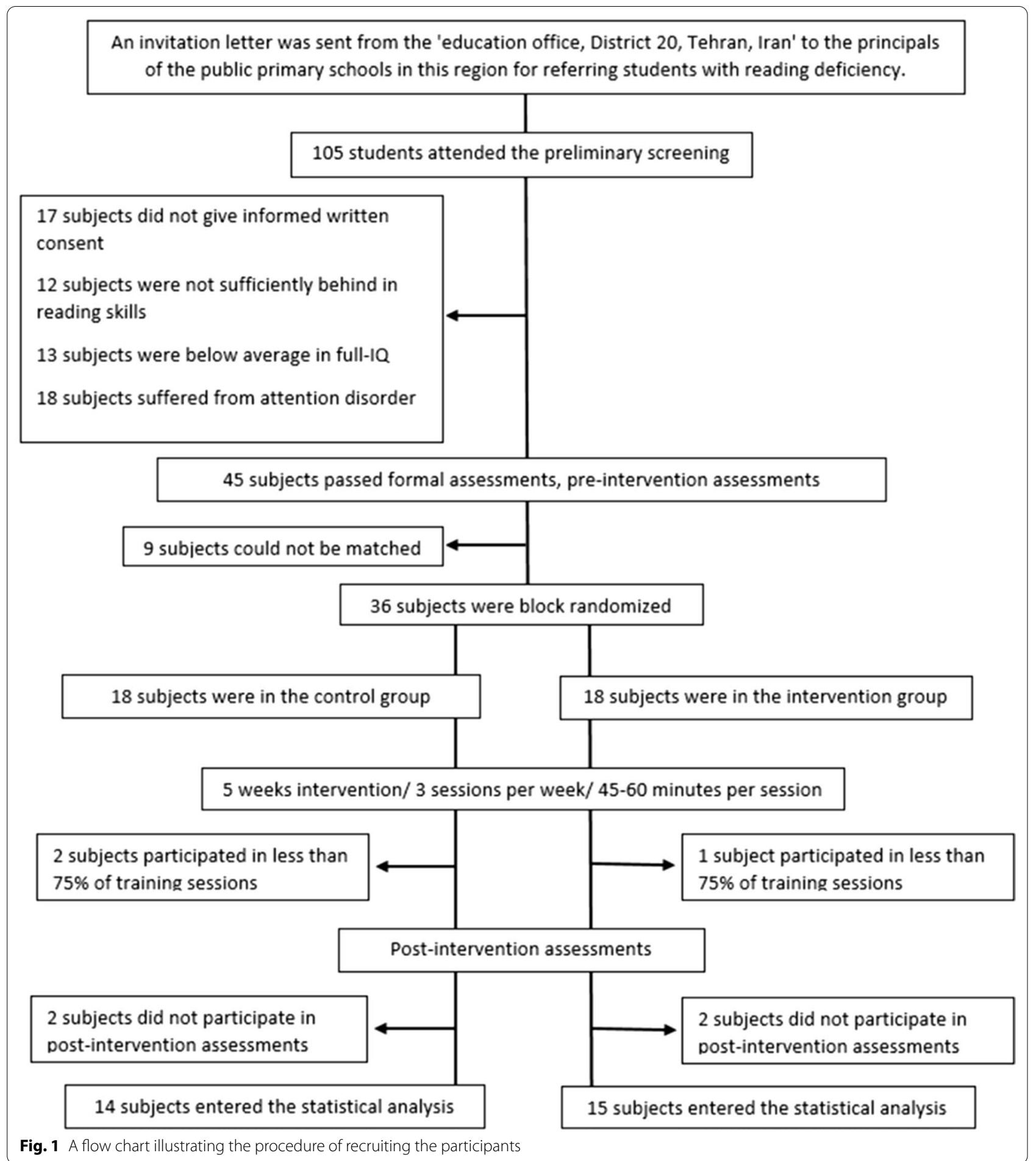

\section{Training programs}

Based on Baddeley's theory, verbal WM includes encoding, maintenance and manipulation of verbal information, and retrieval sub-processes [11]. Fundamental steps of programs, used in the present study, were developed with respect to this theory. In the current research, participants in control and intervention groups received training using VWM-program and VWM-B program, respectively. The VWM-program included verbal WM all sub-processes and considered as a form of the current 


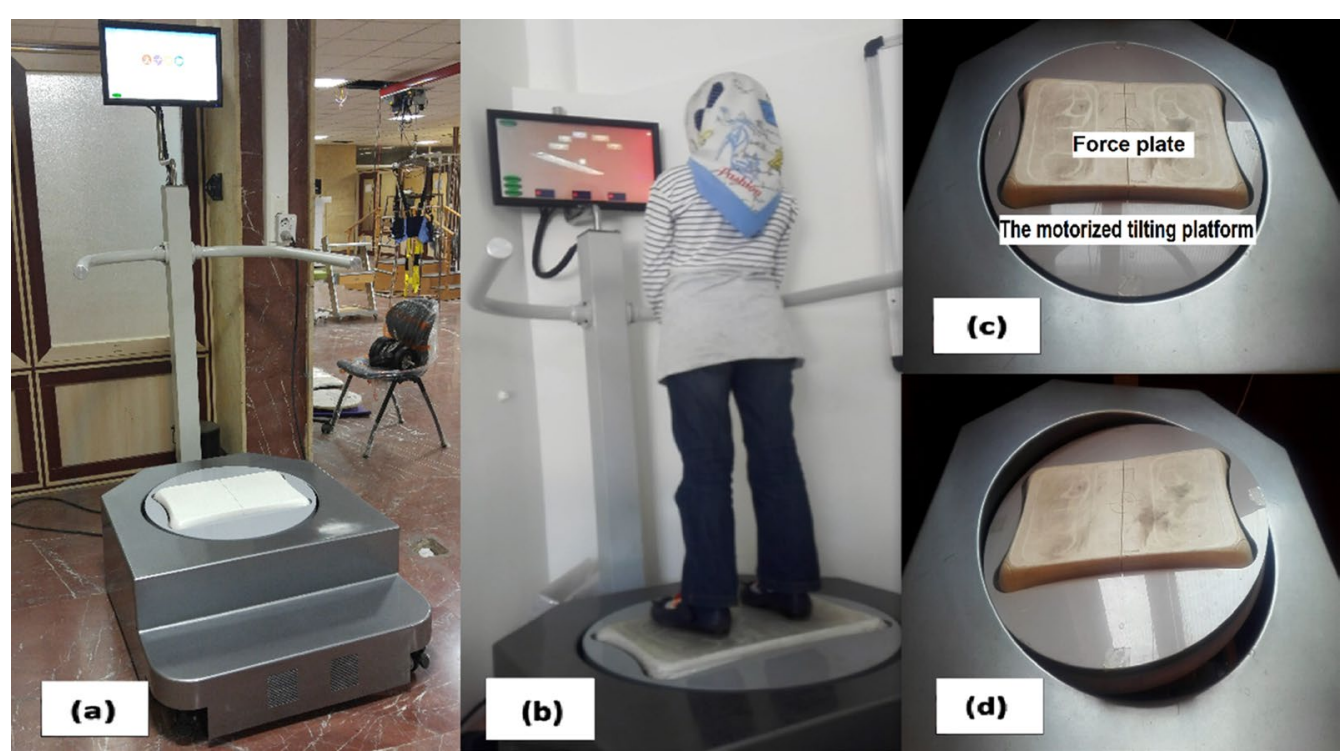

Fig. 2 A robotic device was adopted to implement the new VWM-B training program. a An overview of the robot, $\mathbf{b}$ The whole setup while the subject performs a training trial, c The motorized tilting platform and the force plate, $\mathbf{d}$ An example of the tilting function

training programs $[11,43]$. A portable robotic device was also adopted and developed to perform the newly designed VWM-B program (Fig. 2a and b). The robot consisted of a platform that could be programmed to perform any desired tilting motion in the range of $0^{\circ}-20^{\circ}$ in both anteroposterior and mediolateral, or in a combination of both (Fig. 2c and d). The platform was also equipped with a force plate, with a sampling frequency of $100 \mathrm{~Hz}$ and an accuracy of $\pm 0.4 \mathrm{~mm}$, to measure the CoP [64]. The setup had also a computerized interface using a 19-inch touch screen monitor, and a speaker. The computerized interface ran software that was specially designed for the proposed training program.

\section{VWM-program for participants in the control group}

While training with the VWM-program, the subject sat on a chair in a relaxed mood with arms resting on the table. A 19-inch touch screen monitor ran the software, which was specially designed for the proposed training program, and a speaker was used to recite the words. As mentioned above, each training trial of the VWM-program includes all three sub-processes (encoding, maintenance, and retrieval steps) of the verbal WM. Each trial began $3 \mathrm{~s}$ after touching the start button on the monitor (see the start/stop button in Fig. 3a). For the encoding step, the target, which could be a word, a series of words, or a statement, written inside a box (target box), was shown on the monitor for $10 \mathrm{~s}$ (Fig. 3a). At the same time, the target was recited by playing a pre-recorded voice on the computer. For the maintenance step, the target was decomposed to its components (sentence to its words or word to its letters) and shown on the monitor inside separate boxes (component boxes) for $10 \mathrm{~s}$ (Fig. 3b). Finally, for the retrieval step, twice as many boxes, which included the practiced components and new ones appeared on the monitor (Fig. 3c). The participant had $10 \mathrm{~s}$ to select and touch the boxes, which had appeared and been recited as a component of the target.

\section{VWM-B program for participants in the intervention group} As stated above, the newly designed VWM-B program has been performed using the robotic device (Fig. 2). Like the VWM-program, each training trial in the VWM-B program includes all three steps of verbal WM. The difference is that balance movements have been combined with the maintenance and retrieval steps of verbal WM. Before the training session, the amplitude of the $\mathrm{CoP}$ movement was calibrated to each participant's limit of stability for safety [65]. Participants' standing condition was controlled for uniformity among subjects. The feet position on the platform was the same for all participants, with an approximate distance of $10 \mathrm{~cm}$ between the feet. Also, the monitor was located at eye level, with a distance of approximately $50 \mathrm{~cm}$ (Fig. 2b).

For the encoding step, similar to the VWM-program, a trial began $3 \mathrm{~s}$ after touching the start button on the monitor, and the main target box appeared on the monitor for $10 \mathrm{~s}$ (Fig. 3a). Then, the component boxes appeared on the screen. In addition to the component boxes, a red circle (CoP marker) also appeared on the screen (Fig. 3b). 
This circle represented the position of the subject's CoP and was used to introduce balance tasks to the program.

As a new method, training the maintenance and manipulation of information was performed in two forms: passive and active balance. In the passive state, the motorized moving platform underneath the subject's feet was tilted and the CoP marker was correspondingly moved toward the component boxes implying a passive exercise (see Figs. 2b, d, and 3b). After the component box was hit by the CoP marker, the participant had $10 \mathrm{~s}$ to recite the word inside the box. Then, the platform and the CoP marker returned to the start position (Fig. 3b). This procedure was repeated for all component boxes in the correct order. In the active state, the platform had no tilting motion, and the subject had to actively move his CoP towards the component boxes using ankle/hip strategies. After hitting each component box, the participant attempted to read the word aloud without time limitation. Following reading the word, he returned to the start position and repeated the procedure for all component boxes. In sum, the maintenance step of the VWM-program was $10 \mathrm{~s}$. However, the maintenance step in the VWM-B program included two phases: (1) the passive state that limited for $10 \mathrm{~s}$, and (2) the active state that the subject had free time to read the word. Retrieving information in the VWM-B program was similar to the VWM-program except that the subject had $10 \mathrm{~s}$ to select the response option using his CoP movements (Fig. 3d).

In sum, the encoding step is similar in both programs. Also, the target box decomposes to component boxes in the maintenance step of both two programs. In the VWM-program, a subject observes the monitor and attempts to maintain targets in the memory. However, in the VWM-B program, the maintenance step is performed in two forms: passive and active balance. In the passive state, the component box is automatically hit by the CoP marker; however, in the active state, the subject actively moves the CoP marker to hit the component boxes. For the retrieval step in the VWM-program, the target is shown and the user should accept or reject recalling the target. However, in the VWM-B program's retrieval step, the subject has to move his CoP to select the target.

To make training trials progressively more difficult in both programs and selecting suitable words to practice, we considered factors that impacted on the verbal WM, including phonological similarity, word length, articulatory suppression, and irrelevant sound effects [11]. Training trials for sessions were determined based on the subject's capacity in verbal WM and reading. In the maintenance step of the VWM-B program, the main target box was decomposed to 2-9 component boxes (Fig. 3b). In the passive state, the duration of the marker/platform displacement was adjustable between 3 and $10 \mathrm{~s}$. Also, to further the balance challenge, the component boxes were placed at different distances from the start position button (Fig. 3b).

\section{Assessments}

Five subtests of the NEMA [51] were used to confirm the existence of DD and provide the pre-intervention and post-intervention assessments. The selected NEMA subtests included the WR, NWR, phoneme deletion, text comprehension, and word chain. Also, the oldest and widely used measure of Forward Digit Span (FDS) was employed to test the verbal WM capacity $[66,67]$.

The Stroop color-word test was used to measure changes in selective attention [68-70]. This validated test includes three components. In the color-naming component, the subject is asked to name the color of 176 bars with colors of red, blue, green, and yellow. In the wordnaming component, the subject is asked to read a series of color words including 176 words with colors of red, blue, green, and yellow. Here, the subject reads the word by ignoring its color. In the color-word component, the subject is asked to name the color of words presented in the word-naming component by ignoring their printed form $[68,71]$. In the current research, the time for each component was recorded. Then, the color-word interference was calculated as the time of the third component minus the time of the second component [71].

To assess the postural stability, the CoP data were collected with a portable customized force plate [64]. The force plate was linked via a cable connection to the computer. Data were collected at a sampling rate of $100 \mathrm{~Hz}$ [64]. Recording of the CoP data was performed in a quiet stance with two conditions eyes open and closed. For each condition, two recordings, with a duration of $70 \mathrm{~s}$, was recorded and the

(See figure on next page.)

Fig. 3 Training steps of the Verbal Working Memory (VWM) and VWM-Balance (VWM-B) programs. a Encoding step that is similar in both programs. b In the maintenance step, the target box decomposes to component boxes. The center of pressure (CoP) marker and start position button are displayed on the monitor only in the VWM-B program. In the VWM-program, a subject observes the monitor and attempts to maintain targets in the memory. However, in the VWM-B program, the maintenance step is performed in two forms: passive and active balance. In the passive state, the component box automatically hit by the CoP marker; however, in the active state, the subject actively moves the CoP marker to hit the component boxes. $\mathbf{c}$ For the retrieval step in the VWM-program, the target is shown and the user should accept or reject recalling the target. $\mathbf{d}$ In the VWM-B program's retrieval step, the subject has to move his CoP to select the target 


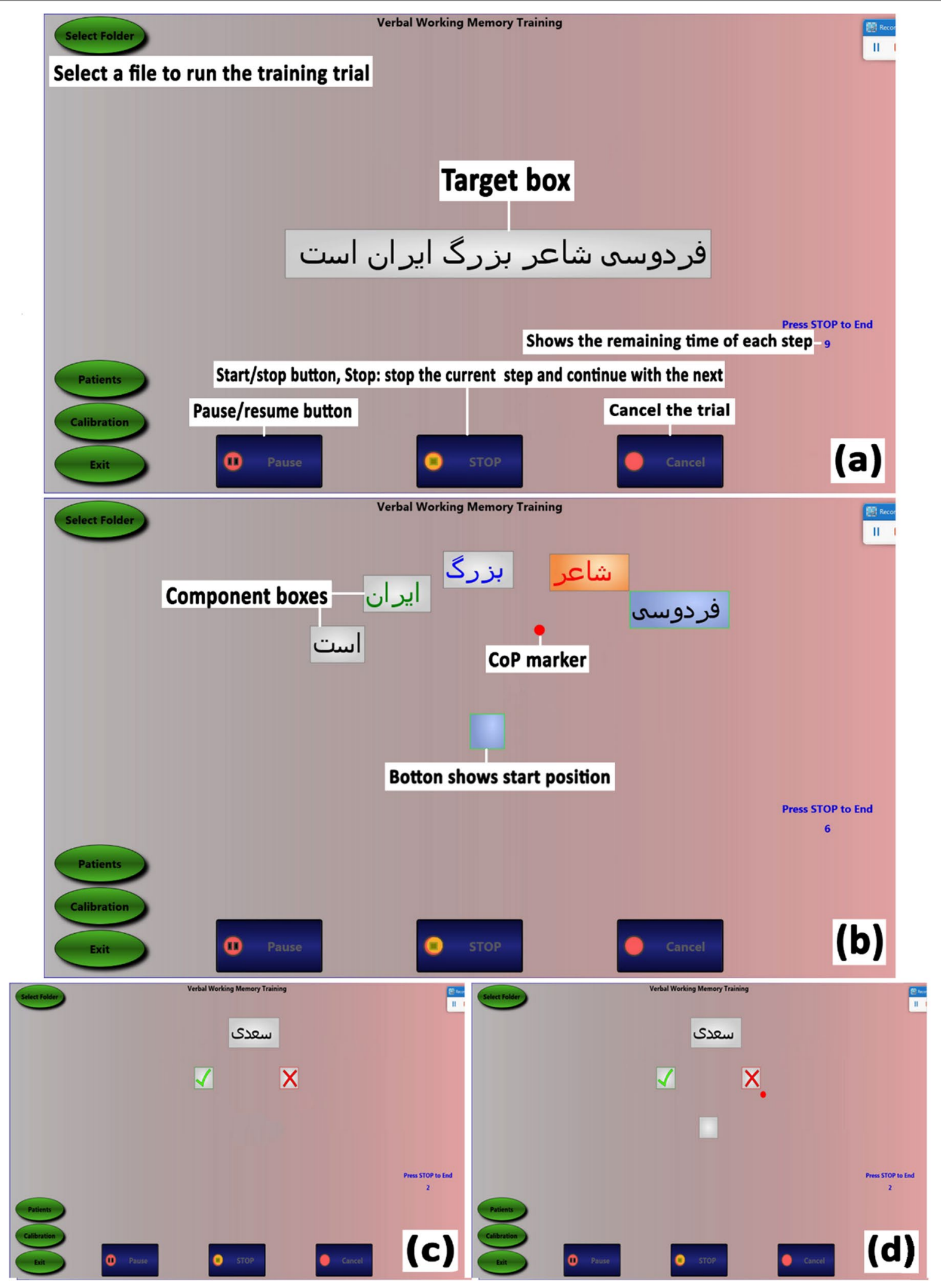

Fig. 3 (See legend on previous page.) 
mean value of parameters were used [72]. In eyes open, the subject's gaze was fixed at a cross mark that was placed on a wall four meters ahead [73]. During the test, participants stood without shoes, with arms folded across the chest. Feet position on the force plate were also marked for inter-trial repeatability. They were instructed to remain still and relaxed in the given stance.

The CoP parameters are suitable to measure postural control in children with DD $[29,74]$. We analyzed the validated parameters of the CoP including the surface area (ellipse with $95 \%$ of CoP excursions), the length (the path length of the CoP), the mean velocity, and the standard deviation in anteroposterior and mediolateral directions [72, 73, 75]. These are efficient measures of the CoP spatial variability and good indices of the amount of neuromuscular activity required to regulate postural control $[29,76]$. After removing the first and the last $5 \mathrm{~s}$ of data, the signals were low-pass filtered using a 4th order Butterworth filter with a cut-off frequency of $10 \mathrm{~Hz}[65,73,77]$. Data was analyzed using Matlab R2016b (MathWorks, MA, USA).

\section{Analysis}

The normality was tested by Shapiro-Wilk [78]. Depending on the distribution of variables, independent $t$-test for parametric variables, Mann-Whitney $U$-test for non-parametric variables, and chi-square test for categorical variables were used to compare groups at baseline $(\alpha=0.05)$. The mean (SD) for quantitative variables and the absolute frequency (\%) for qualitative variables were reported. In the current study, both two groups had received the intervention. Hence, the mixed between-within ANOVA analyses were used to verify the treatment effects over time [79]. Significant interactions $(p<0.05)$ and effect size, with partial eta squared $\left(\eta_{\mathrm{p}}{ }^{2}\right)$, were reported [79]. The $\eta_{\mathrm{p}}{ }^{2}$ is in the family of correlational effect size [80] and is most useful for comparing effect sizes in mixed designs [81]. There are no agreed standards for how to interpret an effect size. Nevertheless, 0.2 is considered a small improvement, 0.5 medium, and 0.8 and above large [80]. Using mixed ANOVA, the effects of training programs on the verbal WM (tested by FDS), reading skills (tested by WR, NWR, phoneme deletion, text comprehension, and word chain subtests of the NEMA), attention (tested by Stroop test), and CoP parameters including the surface area, the length, the mean velocity, and the standard deviation in anteroposterior and mediolateral directions were analyzed. Pearson's correlations between the entire sample gain scores (i.e., the difference between scores in the measurements at pre-intervention and post-intervention) were also reported to explore relationships between the clinical and CoP measures. The SPSS 21 (SPSS Statistics, version 11, IBM, and Armonk, New York, USA) was used to analyze the data.

\section{Results}

The control group contained 14 children with DD, with a mean (SD) age of 8 (1.22) years. The Intervention group included 15 children with DD, with a mean (SD) age of 8 (0.96) years. The hypotheses of normality for height, weight, and full-IQ scores were accepted $(p>0.05)$, and the independent $t$-test showed no significant betweengroup difference at baseline scores. However, the hypotheses of normality for age and CSI-4 scores were rejected $(p<0.05)$, and the Mann-Whitney $U$-test showed no significant between-group difference at baseline scores. As a result, two groups were homogenized $(p>0.05)$ for age, height, weight, full-IQ, and attention, as possible confounders (Table 1). Further information about the demographic characteristics of participants is shown in Table 1. Also, no significant difference $(p>0.05)$ was found for baseline scores of clinical and $\mathrm{CoP}$ measures (see $t$-test outcomes in Table 2). Table 2 also presents the alteration in the mean (SD) of clinical and $\mathrm{CoP}$ measures outcomes after the intervention.

The mixed ANOVA was used to assess the impact of training programs on participants' scores on the FDS, NEMA subtests, and CoP measures (for more information see Table 3). The time main effect was significant for outcome measures of the FDS, reading subtests, and the mean velocity parameter of the $\mathrm{CoP}$ in the eyes-closed condition. These results indicate the alteration in scores after the intervention, regardless of the participants' group. The group main effect was significant for outcome measures of the FDS, WR, and text comprehension subtests of the NEMA. These results demonstrate that scores of these measures changed in groups, regardless of the time effect. The time $\times$ group interaction was also significant for all measures of the FDS, reading subtests, and CoP parameters, except the length, mean velocity, and the standard deviation of mediolateral direction in the eyes-closed condition. When the time $\times$ group interaction is significant, it means that there are differences between the two groups over time.

Pearson's correlation coefficients of the entire sample are reported in Table 4. Some CoP measures in eyes-open and closed conditions were correlated with FDS. The CoP measures, especially in the eyes-open condition, were correlated with reading subtests. The FDS was correlated with reading subtests. The Stroop test was also correlated only with the WR subtest of NEMA. 
Table 1 Demographic characteristics

\begin{tabular}{|c|c|c|c|c|}
\hline Demography & CG $(n=14)$ & IG $(n=15)$ & Total $(\mathrm{N}=29)$ & Group differences ( $p$-value) \\
\hline \multicolumn{5}{|l|}{ Mean (SD) } \\
\hline Age (years) & $8(1.22)$ & $8(0.96)$ & $8(1.12)$ & $u=74.50(0.158)$ \\
\hline Height (cm) & $129(11.65)$ & $119(9.93)$ & $124(11.58)$ & $\mathrm{t}=-2.28(0.277)$ \\
\hline Weight (kg) & $31.21(8.68)$ & $26.20(6.18)$ & $28.62(7.79)$ & $\mathrm{t}=-1.78(0.230)$ \\
\hline WISC-IV (total score) & $91.86(4.11)$ & $95.07(6.56)$ & $93.52(5.66)$ & $t=1.59(0.820)$ \\
\hline $\begin{array}{l}\text { CSI-4, parent checklist (total scores of } \\
1 \text { to } 18 \text { items) }\end{array}$ & $2.59(2.14)$ & $3.41(2.61)$ & $3.00(2.39)$ & $u=82.50(0.316)$ \\
\hline \multicolumn{5}{|l|}{ Frequency (\%) } \\
\hline \multicolumn{5}{|l|}{ Gender } \\
\hline Boy & $5(35.70)$ & $3(20.00)$ & $8(27.60)$ & $x^{2}=0.89(0.344)$ \\
\hline Girl & $9(64.30)$ & $12(80.00)$ & $21(72.40)$ & \\
\hline \multicolumn{5}{|l|}{ Disability } \\
\hline Reading & $5(35.70)$ & $2(13.30)$ & $7(24.10)$ & $x^{2}=5.73(0.126)$ \\
\hline Reading/writing & $4(28.60)$ & $10(66.70)$ & $14(48.30)$ & \\
\hline Reading/math & $0(0.00)$ & $1(6.70)$ & $1(3.40)$ & \\
\hline Reading/writing/math & $5(35.70)$ & $2(13.30)$ & $7(24.10)$ & \\
\hline \multicolumn{5}{|l|}{ School grade } \\
\hline First & $6(42.90)$ & $8(53.30)$ & $14(48.30)$ & $x^{2}=5.70(0.058)$ \\
\hline Second & $1(7.10)$ & $5(33.30)$ & $6(20.70)$ & \\
\hline Third & $7(50.00)$ & $2(13.30)$ & $9(31.00)$ & \\
\hline
\end{tabular}

No significant differences were found on demographic data between children with dyslexia in the control and intervention groups

WISC-IV Wechsler intelligence scale for children-fourth edition, CSI-4 child symptoms inventory, CG control group, IG intervention group

Table 2 Mean (standard deviation) of the clinical and center of pressure measures

\begin{tabular}{|c|c|c|c|c|c|c|c|}
\hline \multirow[t]{2}{*}{ Outcomes } & \multicolumn{2}{|l|}{ CG $(n=14)$} & \multicolumn{2}{|l|}{ IG $(n=15)$} & \multicolumn{2}{|l|}{ Total $(\mathrm{N}=29)$} & \multirow[t]{2}{*}{$\mathrm{T}$ ( $p$-value) } \\
\hline & Pre & Post & Pre & Post & Pre & Post & \\
\hline \multicolumn{8}{|c|}{ Clinical measures } \\
\hline FDS & $4.28(0.91)$ & $5.43(1.39)$ & $4.07(1.03)$ & $7.60(1.72)$ & $4.17(0.96)$ & $6.55(1.90)$ & $-0.61(0.998)$ \\
\hline SCWT & $180.79(56.97)$ & $146.21(66.91)$ & $144.87(84.20)$ & $83.27(85.13)$ & $162.21(73.38)$ & 113.65 (82.02) & $-0.35(0.198)$ \\
\hline WR & $40.14(30.91)$ & $55.93(27.87)$ & $43.67(26.42)$ & $118.80(67.29)$ & $41.97(28.21)$ & 88.45 (60.39) & $0.33(0.303)$ \\
\hline NWR & $12.07(4.32)$ & $14.35(4.60)$ & $11.47(5.39)$ & $22.33(8.56)$ & $11.76(4.83)$ & $18.48(7.93)$ & $-0.33(0.300)$ \\
\hline PD & $13.36(9.86)$ & $17.14(10.11)$ & $15.67(9.24)$ & $25.40(6.83)$ & $14.55(9.44)$ & $21.41(9.40)$ & $0.65(0.606)$ \\
\hline TC & $3.21(1.67)$ & $4.35(1.94)$ & $3.93(1.33)$ & $6.13(1.18)$ & 3.59 (1.52) & $5.27(1.81)$ & $1.27(0.266)$ \\
\hline CW & $12.50(7.73)$ & $17.21(8.63)$ & $10.27(7.01)$ & $29.13(15.9)$ & $11.34(7.32)$ & $23.37(13.61)$ & $-0.81(0.558)$ \\
\hline \multicolumn{8}{|l|}{ CoP measures } \\
\hline QO-L (cm) & $113.56(40.50)$ & $126.03(44.85)$ & 107.82 (23.09) & $95.77(26.03)$ & $110.59(32.20)$ & 110.38 (39.09) & $-0.47(0.647)$ \\
\hline $\mathrm{QO}-\mathrm{A}\left(\mathrm{cm}^{2}\right)$ & $7.11(4.56)$ & $8.62(4.97)$ & 7.97 (3.50) & $5.35(2.77)$ & $7.56(4.00)$ & $6.93(4.25)$ & $0.57(0.576)$ \\
\hline QO-MV $(\mathrm{cm} / \mathrm{s})$ & $1.90(0.67)$ & $2.10(0.74)$ & $1.80(0.38)$ & $1.60(0.44)$ & $1.84(0.54)$ & $1.84(0.65)$ & $-0.47(0.647)$ \\
\hline QO-AP (SD) & $0.61(0.22)$ & $0.72(0.28)$ & $0.66(0.18)$ & $0.53(0.11)$ & $0.64(0.20)$ & $0.62(0.23)$ & $0.72(0.480)$ \\
\hline QO-ML (SD) & $0.55(0.18)$ & $0.57(0.19)$ & $0.61(0.18)$ & $0.48(0.15)$ & $0.58(0.18)$ & $0.52(0.17)$ & $0.85(0.405)$ \\
\hline QC-L (cm) & $142.95(39.91)$ & $135.72(35.81)$ & 138.39 (30.19) & $128.43(35.39)$ & $140.59(34.12)$ & 131.95 (35.15) & $-0.35(0.729)$ \\
\hline $\mathrm{QC}-\mathrm{A}\left(\mathrm{cm}^{2}\right)$ & $8.72(5.16)$ & $9.52(5.63)$ & $9.14(4.23)$ & $7.76(4.34)$ & $8.93(4.62)$ & $8.61(4.99)$ & 0.24 (0.809) \\
\hline QC-MV (cm/s) & $2.38(0.65)$ & $2.26(0.59)$ & $2.31(0.50)$ & $2.12(0.58)$ & $2.34(0.57)$ & $2.19(0.58)$ & $-0.35(0.729)$ \\
\hline QC-AP (SD) & $0.70(0.24)$ & $0.81(0.27)$ & $0.77(0.23)$ & $0.67(0.16)$ & $0.73(0.23)$ & $0.74(0.23)$ & $0.83(0.415)$ \\
\hline QC-ML (SD) & $0.59(0.24)$ & $0.56(0.23)$ & $0.59(0.15)$ & $0.53(0.17)$ & $0.59(0.19)$ & $0.55(0.19)$ & $-0.01(0.996)$ \\
\hline
\end{tabular}

FDS forward digit span, SCWT Stroop color-word test, $W R$ word reading, NWR non-word reading, $P D$ phoneme deletion, $T C$ text comprehension, $C W$ chain word, CoP center of pressure, $Q O$ quite stance-open eyes, $L$ length, $A$ area, $M V$ mean velocity, $A P$ anterior-posterior, $M L$ medial-lateral, $Q C$ quite stance-closed eyes, $C G$ control group, IG intervention group, Pre pre-intervention, Post post-intervention 
Table 3 Outcomes of mixed between-within ANOVA analyses

\begin{tabular}{|c|c|c|c|c|c|c|c|c|c|}
\hline \multirow[t]{2}{*}{ Outcomes } & \multicolumn{3}{|l|}{ Time $^{a}$} & \multicolumn{3}{|c|}{ Group $^{a}$} & \multicolumn{3}{|c|}{ Interaction } \\
\hline & $\begin{array}{l}f \\
(1-27)\end{array}$ & $p$-value & $n_{p}^{2}$ & $\begin{array}{l}f \\
(1-27)\end{array}$ & $p$-value & $n_{p}^{2}$ & $\begin{array}{l}f \\
(1-27)\end{array}$ & $p$-value & $\eta_{p}^{2}$ \\
\hline \multicolumn{10}{|c|}{ Clinical measures } \\
\hline FDS & 103.15 & $<0.001$ & 0.79 & 5.17 & 0.031 & 0.16 & 26.95 & $<0.001$ & 0.5 \\
\hline SCWT & 58.05 & $<0.001$ & 0.68 & 3.35 & 0.078 & 0.11 & 4.58 & 0.041 & 0.15 \\
\hline WR & 47.89 & $<0.001$ & 0.64 & 5.47 & 0.027 & 0.17 & 20.4 & $<0.001$ & 0.43 \\
\hline NWR & 33.94 & $<0.001$ & 0.56 & 3.66 & 0.067 & 0.12 & 14.45 & 0.001 & 0.35 \\
\hline PD & 69.08 & $<0.001$ & 0.72 & 2.61 & 0.118 & 0.09 & 13.37 & 0.001 & 0.33 \\
\hline TC & 154.79 & $<0.001$ & 0.85 & 4.94 & 0.035 & 0.16 & 15.48 & 0.001 & 0.36 \\
\hline $\mathrm{CW}$ & 103.15 & $<0.001$ & 0.6 & 2.15 & 0.154 & 0.07 & 14.47 & 0.001 & 0.35 \\
\hline \multicolumn{10}{|l|}{ CoP measures } \\
\hline QO-L (cm) & 0 & 0.972 & 0 & 2.45 & 0.13 & 0.08 & 4.48 & 0.044 & 0.14 \\
\hline QO-A $\left(\mathrm{cm}^{2}\right)$ & 1.37 & 0.252 & 0.05 & 0.73 & 0.401 & 0.03 & 19.11 & $<0.001$ & 0.41 \\
\hline QO-MV (cm/s) & 0 & 0.993 & 0 & 2.41 & 0.132 & 0.08 & 4.39 & 0.046 & 0.14 \\
\hline QO-AP (SD) & 0.07 & 0.79 & 0 & 1.1 & 0.305 & 0.04 & 10.05 & 0.004 & 0.27 \\
\hline QO-ML (SD) & 3.97 & 0.056 & 0.13 & 0.11 & 0.747 & 0 & 9.25 & 0.005 & 0.26 \\
\hline QC-L (cm) & 4.07 & 0.054 & 0.13 & 0.23 & 0.635 & 0.01 & 0.1 & 0.752 & 0 \\
\hline $\mathrm{QC}-\mathrm{A}\left(\mathrm{cm}^{2}\right)$ & 0.31 & 0.584 & 0.01 & 0.15 & 0.704 & 0.01 & 4.52 & 0.043 & 0.14 \\
\hline QC-MV (cm/s) & 4.51 & 0.043 & 0.14 & 0.27 & 0.608 & 0.01 & 0.18 & 0.674 & 0.01 \\
\hline QC-AP (SD) & 0.04 & 0.842 & 0 & 0.14 & 0.711 & 0.01 & 8.34 & 0.008 & 0.24 \\
\hline QC-ML (SD) & 3.41 & 0.076 & 0.11 & 0.05 & 0.83 & 0 & 0.45 & 0.511 & 0.02 \\
\hline
\end{tabular}

Bolded values indicate statistically significant $p$-values $(p<0.05)$

FDS forward digit span, SCWT Stroop color-word test, WR word reading, NWR non-word reading, PD phoneme deletion, TC text comprehension, $C W$ chain word, CoP center of pressure, $Q O$ quite stance-open eyes, $L$ length, $A$ area, $M V$ mean velocity, $A P$ anterior-posterior, $M L$ medial-lateral, $Q C$ quite stance-closed eyes

${ }^{\text {a } B e t w e e n-s u b j e c t s ~ f a c t o r ~ ' G r o u p ' ~}=$ control group vs. intervention group, and within-subjects factor 'Time' $=$ measurement at before and after intervention

We would like to thank an anonymous reviewer for highlighting a slight school-grade difference, which was not significant between the control and the intervention group (see Table 1). Keeping in mind clarification on the teaching system (see more information in Section "Subjects and design" in the "Methods") and in response to this suggestion, we ran further ANOVA analyses on children in grades 2 and 3 , which produced the same pattern of significant results (Tables 5 and 6).

\section{Discussion}

In the current research, we aimed to examine the effectiveness of the VWM-B program on verbal WM capacity, reading ability, and postural control in children with DD. In comparison with VWM-program, the VWM-B program showed superior performance on verbal WM capacity, reading skills, and postural control after a shortterm intervention.

Based on our best knowledge, VWM-B is the only training program, which contains a mix of cognitive and balance-related performance simultaneously, which has been used in DD. Previous studies have also reported some positive effects for a combination of cognitive and physical training in other populations [82-84]. Regarding the sequential nature of the process in a dual-task condition, e.g., the VWM-B program, the nervous system first prioritizes a task and then assigns further cognitive/attentional resources for the prioritized task. Therefore, the performance decreases on the non-priority task [85]. Furthermore, sufficient manipulating and maintaining information in the verbal WM is critical for increasing verbal WM capacity [86]. Keeping these points in mind, the featured maintenance step of the VWM-B program probably had an important role in efficiently improving the measured functions in children with DD (see Section "VWM-B program for participants in the intervention group" in the "Methods"). We designed the maintenance step of the VWM-B program within two passive and active balance states of the subject. In the passive state, we designed the cognitive task as a prioritized task. In the active state, however, the balance was considered a prioritized task. Hence, we expected the balance-related movements would be automatized [75], and as a result, further resources assign to the cognitive task [85]. The cerebellar deficit hypothesis in dyslexia characterizes 
Table 4 Pearson correlation between measures $r$ ( $p$-value)

\begin{tabular}{|c|c|c|c|c|c|c|c|}
\hline Outcomes & FDS & SCWT & WR & NWR & PD & $\mathrm{TC}$ & CW \\
\hline \multicolumn{8}{|c|}{ Clinical measures } \\
\hline SCWT & $-0.28(0.148)$ & - & - & - & - & - & - \\
\hline WR & $0.70^{* *}\left({ }^{<} \mathbf{0 . 0 0 1}\right)$ & $-0.36^{*}(\mathbf{0 . 0 4 5})$ & - & - & - & - & - \\
\hline NWR & $0.61^{* *}\left({ }^{<} \mathbf{0 . 0 0 1}\right)$ & $-0.13(0.495)$ & $0.51^{* *}(\mathbf{0 . 0 0 5})$ & - & - & - & - \\
\hline PD & $0.41^{*}(0.027)$ & $-0.16(0.410)$ & $0.46^{*}(\mathbf{0 . 0 1 3})$ & $0.41^{*}(\mathbf{0 . 0 2 8})$ & - & - & - \\
\hline $\mathrm{TC}$ & $0.36(0.056)$ & $-0.20(0.301)$ & $0.34(0.069)$ & $0.45^{*}(\mathbf{0 . 0 1 5})$ & $0.47^{* *}(\mathbf{0 . 0 1 0})$ & - & - \\
\hline CW & $0.60^{* *}(\mathbf{0 . 0 0 1})$ & $-0.25(0.184)$ & $0.87^{* *}(\mathbf{0 . 0 0 1})$ & $0.41^{*}(\mathbf{0 . 0 2 6})$ & $0.39 *(\mathbf{0 . 0 3 8})$ & $0.35(0.060)$ & - \\
\hline \multicolumn{8}{|l|}{ CoP measures } \\
\hline QO-L (cm) & $-0.25(0.186)$ & $0.05(0.814)$ & $-0.39^{*}(\mathbf{0 . 0 3 5 )}$ & $-0.26(0.167)$ & $-0.50^{* *}(\mathbf{0 . 0 0 6})$ & $0.01(0.970)$ & $-0.26(0.179)$ \\
\hline QO-A $\left(\mathrm{cm}^{2}\right)$ & $-0.52^{* *}(\mathbf{0 . 0 0 4})$ & $0.20(0.303)$ & $-0.58^{* *}(\mathbf{0 . 0 0 1})$ & $-0.42^{*}(\mathbf{0 . 0 2 4})$ & $-0.47^{*}(\mathbf{0 . 0 1 0})$ & $-0.38^{*}(0.045)$ & $\begin{array}{l}-0.44^{*} \\
(0.017)\end{array}$ \\
\hline QO-MV (cm/s) & $-0.25(0.187)$ & $0.05(0.816)$ & $-0.39^{*}(\mathbf{0 . 0 3 6})$ & $-0.26(0.169)$ & $-0.50^{* *}(\mathbf{0 . 0 0 6})$ & $0.016(0.936)$ & $-0.26(0.181)$ \\
\hline QO-AP (SD) & $-0.29(0.130)$ & $0.15(0.433)$ & $-0.42^{*}(\mathbf{0 . 0 2 3})$ & $-0.18(0.342)$ & $-0.33(0.079)$ & $-0.22(0.253)$ & $-0.35(0.066)$ \\
\hline QO-ML (SD) & $-0.60^{* *}(\mathbf{0 . 0 0 1})$ & $0.06(0.739)$ & $-0.56^{* *}(\mathbf{0 . 0 0 2})$ & $-0.52^{* *}(\mathbf{0 . 0 0 4})$ & $-0.45^{*}(\mathbf{0 . 0 1 4})$ & $-0.45^{*}(\mathbf{0 . 0 1 5})$ & $\begin{array}{l}-0.46^{*} \\
(\mathbf{0 . 0 1 1 )}\end{array}$ \\
\hline QC-L (cm) & $-0.18(0.351)$ & $0.13(0.495)$ & $-0.33(0.077)$ & $0.06(0.759)$ & $-0.18(0.345)$ & $0.10(0.618)$ & $-0.31(0.106)$ \\
\hline $\mathrm{QC}-\mathrm{A}\left(\mathrm{cm}^{2}\right)$ & $-0.47^{* *}(\mathbf{0 . 0 1 0})$ & $0.17(0.368)$ & $-0.26(0.150)$ & $-0.16(0.415)$ & $-0.25(0.197)$ & $-0.04(0.849)$ & $-0.26(0.177)$ \\
\hline QC-MV (cm/s) & $-0.20(0.307)$ & $0.14(0.486)$ & $-0.36(0.053)$ & $0.05(0.806)$ & $-0.19(0.319)$ & $0.09(0.647)$ & $-0.31(0.107)$ \\
\hline QC-AP (SD) & $-0.29(0.125)$ & $0.31(0.099)$ & $-0.31(0.097)$ & $-0.16(0.423)$ & $-0.55^{* *}(\mathbf{0 . 0 0 2})$ & $-0.21(0.267)$ & $-0.29(0.127)$ \\
\hline QC-ML (SD) & $-0.41^{*}(\mathbf{0 . 0 2 8})$ & $-0.17(0.388)$ & $-0.22(0.254)$ & $-0.15(0.445)$ & $-0.00(0.986)$ & $0.06(0.744)$ & $-0.17(0.380)$ \\
\hline
\end{tabular}

Bolded values indicate statistically significant $p$-values $(p<0.05)$

FDS forward digit span, SCWT Stroop color-word test, WR word reading, NWR non-word reading, PD phoneme deletion, TC text comprehension, $C W$ chain-word, Co $P$ center of pressure, $Q O$ quite stance-open eyes, $L$ length, $A$ area, $M V$ mean velocity, $A P$ anterior-posterior, $M L$ medial-lateral, $Q C$ quite stance-closed eyes

${ }^{*}$ Correlation is significant at the 0.05 level (2-tailed). ${ }^{*}$ Correlation is significant at the 0.01 level (2-tailed)

the behavioral symptoms of dyslexia as difficulties in skills automatization [16]. Based on this theory, the cerebellum is a key structure in the automatization deficits [87]. Therefore, it appears that the positive effects of the VWM-B program on the measured functions stemmed from its effects on cerebellum activation.

The present study showed improvement in the intervention group participants' postural control after the intervention, which was perceived in both eyes open and closed conditions of CoP. It indicates that the balancerelated movements were automatized after the intervention. The older evidence revealed that there is no significant difference between the upright standing postural control (eyes open) of the dyslexic and non-dyslexic children [88]. However, children with DD have weaker postural control when they use visual information to perform an activity (actions often are complex or dual-task) $[34,88]$. The reason is supposedly insufficient coupling of the visual inputs and postural sway while performing an activity [88]. The improved postural control in the eyes-open condition demonstrates that coupling visual information and body sway were probably improved, and the intervention group participants could assign sensory information to produce purposeful actions [88]. In other words, these participants showed higher performance in using non-visual information to maintain postural control and benefit from the visual information to perform purposeful (cognitive) actions. The improved postural control in the eyes-closed condition implies that the intervention group participants probably benefited from vestibular and/or proprioceptive information and were less dependent on visual inputs to maintain postural control [89]. Since there were no significant changes in the $\mathrm{CoP}$ measures of the control group participants, it is concluded that the motor strategies relating to balance control were automatized [75, 88, 90, 91], and further neural resources were allocated to the cognitive task following the intervention by the VWM-B program [85, 90, 91].

In the present study, participants who had received training by the VWM-B program showed higher performance in verbal WM and reading skills. Also, the current research demonstrated that improved postural control was correlated with verbal WM and reading ability. Furthermore, verbal WM was correlated with reading ability. Although the current research has emphasized the cerebellar deficits hypothesis to interpret the results, the causal link between the balance deficits and reading problems is still under controversy [74, 92-94]. On the other hand, literature has confirmed the critical role of the cerebellum in verbal WM deficits [32]. Hence, it 
Table 5 Outcomes of mixed between-within ANOVA analyses for the sum of the second and third grade students, when the firstgraders were excluded

\begin{tabular}{|c|c|c|c|c|c|c|c|c|c|}
\hline \multirow[t]{2}{*}{ Outcomes } & \multicolumn{3}{|l|}{ Time $^{a}$} & \multicolumn{3}{|c|}{ Group $^{a}$} & \multicolumn{3}{|c|}{ Interaction } \\
\hline & $\begin{array}{l}f \\
(1-13)\end{array}$ & $p$-value & $\eta_{p}^{2}$ & $\begin{array}{l}f \\
(1-13)\end{array}$ & $p$-value & $n_{p}^{2}$ & $\begin{array}{l}f \\
(1-13)\end{array}$ & $p$-value & $\eta_{p}^{2}$ \\
\hline \multicolumn{10}{|l|}{ Clinical measures } \\
\hline FDS & 73.16 & $<0.001$ & 0.86 & 18.62 & 0.001 & 0.61 & 20.1 & 0.001 & 0.63 \\
\hline SCWT & 14.1 & 0.003 & 0.54 & 0.29 & 0.603 & 0.02 & 0.42 & 0.531 & 0.03 \\
\hline WR & 45.16 & $<0.001$ & 0.79 & 26.3 & $<0.001$ & 0.69 & 26.3 & $<0.001$ & 0.69 \\
\hline NWR & 16.16 & 0.002 & 0.57 & 1.89 & 0.194 & 0.14 & 8.29 & 0.014 & 0.41 \\
\hline PD & 56.34 & $<0.001$ & 0.82 & 0.9 & 0.37 & 0.07 & 17.12 & 0.001 & 0.59 \\
\hline $\mathrm{TC}$ & 57.83 & $<0.001$ & 0.83 & 0.09 & 0.77 & 0.01 & 5.79 & 0.033 & 0.33 \\
\hline$C W$ & 22.54 & $<0.001$ & 0.65 & 1.19 & 0.296 & 0.09 & 10.07 & 0.008 & 0.46 \\
\hline \multicolumn{10}{|l|}{ CoP measures } \\
\hline QO-L (cm) & 0.22 & 0.647 & 0.02 & 3.62 & 0.081 & 0.23 & 1.47 & 0.25 & 0.2 \\
\hline QO-A $\left(\mathrm{cm}^{2}\right)$ & 1.94 & 0.189 & 0.14 & 1.07 & 0.321 & 0.08 & 16.46 & 0.002 & 0.58 \\
\hline QO-MV (cm/s) & 0.25 & 0.628 & 0.02 & 3.56 & 0.084 & 0.23 & 1.41 & 0.258 & 0.11 \\
\hline QO-AP (SD) & 0.24 & 0.639 & 0.02 & 1.17 & 0.301 & 0.09 & 10.05 & 0.004 & 0.27 \\
\hline QO-ML (SD) & 10.05 & 0.008 & 0.46 & 0.09 & 0.765 & 0.01 & 16.84 & 0.001 & 0.58 \\
\hline QC-L (cm) & 1.9 & 0.195 & 0.14 & 0.78 & 0.396 & 0.06 & 0 & 0.993 & 0 \\
\hline $\mathrm{QC}-\mathrm{A}\left(\mathrm{cm}^{2}\right)$ & 0.22 & 0.644 & 0.02 & 0.38 & 0.551 & 0.03 & 1.8 & 0.204 & 0.13 \\
\hline QC-MV (cm/s) & 2.36 & 0.151 & 0.16 & 0.93 & 0.353 & 0.07 & 0.03 & 0.864 & 0 \\
\hline QC-AP (SD) & 0.03 & 0.866 & 0 & 0.08 & 0.783 & 0 & 6.27 & 0.028 & 0.34 \\
\hline QC-ML (SD) & 2.23 & 0.161 & 0.16 & 0.08 & 0.782 & 0 & 0.03 & 0.861 & 0 \\
\hline
\end{tabular}

Bolded values indicate statistically significant $p$-values $(p<.05)$

FDS forward digit span, SCWT Stroop color-word test, WR word reading, NWR non-word reading, $P D$ phoneme deletion, TC text comprehension, $C W$ chain word, CoP center of pressure, $Q O$ quite stance-open eyes, $L$ length, $A$ area, $M V$ mean velocity, $A P$ anterior-posterior, $M L$ medial-lateral, $Q C$ quite stance-closed eyes

${ }^{\text {a }}$ Between-subjects factor 'Group' $=$ control group vs. intervention group, and within-subjects factor 'Time' $=$ measurement at before and after intervention

appears that the automatized postural control initially caused an improvement in verbal WM capacity; and thereupon, the increased verbal WM capacity has led to an improvement in reading ability [95]. It seems that the improved verbal WM capacity facilitated the word and non-word reading ability via improved phonological awareness (tested by the WR and phoneme deletion subtests of NEMA) [96, 97]. Also, improvement in the grapheme-phoneme decoding (tested by the NWR and word chain subtests of NEMA) and phonemic awareness (tested by the WR and phoneme deletion subtests of NEMA) may be related to an improvement in reading comprehension (tested by the text comprehension subtest of NEMA) [97, 98]. In the case of attention, the close link between WM capacity and attention has been confirmed by previous studies [99]. It has been reported that the WM modulates attention [69, 99, 100], and on the other hand, that attention promotes the encoding, maintaining, and manipulating of information in the WM $[101,102]$. Despite these pieces of evidence, the Stroop test outcomes in the present study were uncorrelated with verbal WM capacity. Decreasing in the Stroop interference was correlated only with the WR subtest of NEMA. The significantly decreased Stroop interference in the intervention group participants could be justified by the structure of Stroop test. The word-naming step of the Stroop needs the subject to read the colored words [68]. It shows the subjects' reading rate and reflects their speech-motor problems $[68,71]$. Children with DD usually spend further time to complete this component [68, 70]. Keeping this point in mind, the decreased Stroop interference in the current study probably resulted from the improvement in word reading ability (tested by the WR subtest of NEMA). This claim is supported by previous studies when they declared that decreased Stroop interference implies improvements in reading ability as well as selective attention [68-70].

The cerebellar deficit hypothesis has also emphasized the impairments in the procedural learning system, with specific deficits in the language/cerebellar procedural circuits [87]. Almost all human activity needs trial-anderror (supervised) learning, which is a sub-type of procedural learning [87]. The cerebellum is a central structure in human brain circuits, and it is a crucial point that only 
Table 6 Mean (standard deviation) of the clinical and center of pressure measures for the sum of the second and third grade students, when the first-graders were excluded

\begin{tabular}{|c|c|c|c|c|c|c|}
\hline \multirow[t]{2}{*}{ Outcomes } & \multicolumn{2}{|l|}{ CG $(n=8)$} & \multicolumn{2}{|l|}{ IG $(n=7)$} & \multicolumn{2}{|l|}{ Total $(\mathrm{N}=15)$} \\
\hline & Pre & Post & Pre & Post & Pre & Post \\
\hline \multicolumn{7}{|l|}{ Clinical measures } \\
\hline FDS & $2.50(0.53)$ & $3.12(0.64)$ & $2.83(0.41)$ & $4.83(0.41)$ & $2.64(0.50)$ & $3.86(1.02)$ \\
\hline SCWT & $192.50(63.89)$ & $160.00(73.13)$ & 180.00 (75.96) & $134.00(64.83)$ & $187.14(66.77)$ & $148.86(68.37)$ \\
\hline WR & $57.13(27.94)$ & $69.13(26.62)$ & 52.16 (29.99) & $141.50(65.28)$ & $55.00(27.80)$ & $100.14(58.33)$ \\
\hline NWR & $12.63(4.41)$ & $14.50(4.84)$ & $12.50(6.19)$ & $23.83(11.43)$ & $12.57(5.02)$ & $18.50(9.26)$ \\
\hline PD & $16.90(11.40)$ & $20.25(11.27)$ & $17.50(8.10)$ & $29.17(3.77)$ & $17.14(9.74)$ & $24.10(9.74)$ \\
\hline TC & $3.90(1.90)$ & $5.00(2.27)$ & $3.67(1.86)$ & $5.83(1.60)$ & $3.79(1.81)$ & $5.36(1.98)$ \\
\hline$C W$ & $17.25(6.19)$ & $21.63(9.04)$ & $13.67(8.64)$ & $35.67(1.17)$ & $15.71(7.26)$ & $27.64(14.02)$ \\
\hline \multicolumn{7}{|l|}{ CoP measures } \\
\hline QO-L (cm) & $119.76(45.47)$ & $126.84(50.93)$ & 96.15 (21.72) & $80.10(11.10)$ & $109.64(37.10)$ & $106.80(45.05)$ \\
\hline $\mathrm{QO}-\mathrm{A}\left(\mathrm{cm}^{2}\right)$ & $6.57(3.85)$ & $8.48(4.89)$ & 7.57 (3.50) & $3.67(1.85)$ & $7.00(3.28)$ & $6.42(4.50)$ \\
\hline QO-MV (cm/s) & $2.00(0.76)$ & $2.11(0.85)$ & $1.60(0.36)$ & $1.30(0.20)$ & $1.83(0.63)$ & $1.80(0.75)$ \\
\hline QO-AP (SD) & $0.61(0.22)$ & $0.76(0.35)$ & $0.67(0.22)$ & $0.46(0.08)$ & $0.64(0.21)$ & $0.63(0.30)$ \\
\hline QO-ML (SD) & $0.55(0.21)$ & $0.58(0.20)$ & $0.64(0.16)$ & $0.43(0.20)$ & $0.59(0.19)$ & $0.51(0.21)$ \\
\hline QC-L (cm) & 144.39 (37.69) & 135.81 (33.77) & $130.23(20.05)$ & $121.76(29.53)$ & $138.32(31.18)$ & $129.79(31.65)$ \\
\hline QC-A $\left(\mathrm{cm}^{2}\right)$ & $8.96(5.56)$ & $9.80(5.70)$ & $8.75(3.65)$ & 7.02 (3.13) & $8.87(4.65)$ & $8.61(4.81)$ \\
\hline QC-MV $(\mathrm{cm} / \mathrm{s})$ & $2.41(0.63)$ & $2.30(0.56)$ & $2.17(0.33)$ & $2.00(0.46)$ & $2.31(0.52)$ & $2.15(0.52)$ \\
\hline QC-AP (SD) & $0.72(0.23)$ & $0.86(0.28)$ & $0.84(0.32)$ & $0.68(0.14)$ & $0.77(0.27)$ & $0.78(0.24)$ \\
\hline QC-ML (SD) & $0.62(0.29)$ & $0.56(0.21)$ & $0.58(0.12)$ & $0.53(0.14)$ & $0.60(0.22)$ & $0.55(0.18)$ \\
\hline
\end{tabular}

FDS forward digit span, SCWT Stroop color-word test, WR word reading, NWR non-word reading, $P D$ phoneme deletion, $T C$ text comprehension, $C W$ chain word, CoP center of pressure, $Q O$ quite stance-open eyes, $L$ length, $A$ area, $M V$ mean velocity, $A P$ anterior-posterior, $M L$ medial-lateral, $Q C$ quite stance-closed eyes, $C G$ control group, IG intervention group, Pre pre-intervention, Post post-intervention

the cerebellum has a hub circuitry to support supervised learning [87]. It implies that if this type of learning is required (e.g., in reading), it is necessary to involve the cerebellum as part of the circuit, along with the other parts of the brain involved in reading [87] (e.g., cortical regions of perisylvian [6] and prefrontal [23] involved in phonological processing and verbal WM, respectively). The corticocerebellar circuits involve loops from the cortex to the cerebellum to thalamic nuclei and back to the cortex [103]. Insufficient skill automatization due to impaired cerebellar function leads to problems in reading, though via different cerebellar circuits [104]. Considering the findings of the current study for CoP, it seems that the VWM-B program caused changes in the activation of cerebellum circuitry. Some regions of the cerebellum may be activated in this dual-task performance [36] and could integrate motor and cognitive networks and adjust these networks to be more efficient for performing the dual-task properly [36].

Although it needs future neuroimaging studies to adequately investigate the changes in the activation of the cerebellar circuits after treatment with the VWM-B program, previous neuroimaging studies have confirmed the role of the cerebellum in verbal WM, reading, balance, and complex actions $[105,106]$. For example, a loop between the right VI and crus I lobules of the cerebellum and Broca's region of the left frontal lobe activates during articulatory rehearsal and verbal WM tasks [105, 107]. Activation of the right VI and crus I lobules of the cerebellum provide internal motor sequences for the phonological content of words [106]. Also, it has been reported that the loops between the bilateral cerebellar VI and VII lobules and the cerebral regions of the left inferior frontal lobe and the left inferior occipitotemporal lobe have a critical role in the reading network [108, 109]. Furthermore, researchers have recently discovered a novel topographic map in the cerebellar lobules of VI and VIIA, which shows the role of these lobules in complex motor tasks [105]. Therefore, the authors suggest considering these cerebellar regions in future neuroimaging studies by treatment with the VWM-B program.

There are limited studies that investigate balance training effects on children with DD. For example, Goulème et al. demonstrated the effect of balance training only on postural control [28]; however, Reynolds et al. reported the positive effects of the exercise-based treatment on balance, dexterity, eye movement control, and cognitive skills underlying literacy [110]. Whereas Rack et al. 
[111], following a commentary on the Reynolds et al. study [110,111], have not confirmed the reported results. Overall, there were no sufficient balance training methods to improve the balance and literacy in the children with DD. Therefore, the present study has introduced a newly designed training program, for the first time, which has positive effects concurrently on postural control and reading-related cognitive functions in children with DD. However, this study has some limitations. Various differences in the quality of educational services may be observed between different districts in Tehran as a metropolis. Regarding the socio-economic status of participants as an inclusion criterion, study participants were recruited from the public primary schools located in District 20, Tehran, Iran. Therefore, recruitment did not include students of private schools located in this region because of possible different educational services. Moreover, the present study investigated only the shortterm effects of the VWM-B program, and its long-term effectiveness needs to be followed up in the future. We suggest investigating the effectiveness of the VWM-B program on attention using suitable measurements such as eye-tracking studies to investigate visual attention [112] and eye-movement changes, especially fixation [113] as an indicator for improving attention in DD. Also for future studies, a dyslexia control group without interventions should be considered.

\section{Conclusions}

The present study is a pioneer in investigating the effectiveness of a newly structured VWM-B training program. This program provides a dual-task condition including cognitive (verbal WM and reading) and motor (passive and active balance state) tasks. This study demonstrated that the VWM-B program, after the short-term treatment, is more effective than the VWM-program in the improvement of verbal WM capacity, reading skills, and postural control in the children with DD. The improvement in postural control (automatization in the balancerelated movements) probably had an effective role in improving the measured cognitive functions. It seems that the automatization in balance-related movements consequently led to assigning further neural resources to the cognitive task. The Cerebellum has a critical role in maintaining postural control and automatizing skills; therefore, the activation of the cerebellum regions may be changed after the intervention by the VWM-B program. Despite the results of the current studies that support the cerebellar deficits hypothesis, the role of the cerebellum in DD is still controversial.

\section{Abbreviations}

WM: Working memory; VWM-B: Verbal working memory-balance; WISC-IV: Wechsler intelligence scale for children-fourth edition; CSI-4: Child symptoms inventory-four; COP: Center of pressure; NEMA: Persian battery of normative reading tests; WR: Words reading; NWR: Non-words reading; FDS: Forward digit span.

\section{Supplementary Information}

The online version contains supplementary material available at https://doi. org/10.1186/s12868-021-00660-1.

Additional file 1: Appendix S1. CONSORT checklist.

\section{Acknowledgements}

The authors thank the participating families, children, assessors, and education office staff of District 20, Tehran, Iran. Special thanks to Djawad Movafaghian Research Center in Rehabilitation Technologies (DMRCINT), Sharif University of Technology for experimental setup and technical supporting. This research was partially supported by funding from Iran National Science Foundation (INSF) Grant No. 92042014

\section{Authors' contributions}

MR performed the VWM and VWM-B programs design, study design, subject recruitment, data collection, data analysis and interpretation, and initial manuscript preparation. ES, SB, and MTJ coordinated the study. EP involved in data analysis and results critique. AF participated in the study design. MR, EP, AF, and SB participated in the manuscript revision. All authors read and approved the final manuscript.

\section{Funding}

This work was supported by the Iran University of Medical Sciences (Grant Numbers 96-03-87-31977). Authors have used the grant for staff's salaries (for data collection and analysis) and traveling costs. The founder was not involved in the design, method, data collection and analysis, interpretation of data, and writing the manuscript.

\section{Availability of data and materials}

The data analyzed during the current study are available from the corresponding author on reasonable request.

\section{Declarations}

\section{Ethics approval and consent to participate}

Before participation in the study, all parents were notified about the purposes of the research, the study procedures (e.g., random assignment to control and intervention groups), the potential consequences of the study, their right to accept or refuse research participation, their responsibilities as the parents of a child participating in research, and the responsibilities of investigators to parents and children. All parents provided informed written consent before their child's participation in the study, and all children were compensated for their participation. The current study followed the principles of the Declaration of Helsinki. The protocol of the current research, as a part of a Ph.D. thesis, had been approved by the Research Ethics Committee, Iran University of Medical Sciences, Tehran, Iran (IR.IUMS.REC1396.31977). Also, the trial was (retrospectively) registered on 8 February 2018 with the Iranian Registry of Clinical Trials (IRCT20171219037953N1).

\section{Consent for publication}

The image of a child in Fig. 2 has been fully anonymized, and the parent provided informed written consent for using their child's image in the manuscript.

\section{Competing interests}

The authors declare that they have no competing interests. 


\begin{abstract}
Author details
1 Department of Neuroscience, Faculty of Advanced Technologies in Medicine, Iran University of Medical Sciences, Tehran, Iran. ${ }^{2}$ Mechanical Engineering Department, Sharif University of Technology, Tehran, Iran. ${ }^{3}$ Djawad Movafaghian Research Center in Neuro-Rehabilitation Technologies, Sharif University of Technology, Tehran, Iran. ${ }^{4}$ Cellular and Molecular Research Center, Iran University of Medical Sciences, Tehran, Iran. ${ }^{5}$ Mental Health Research Center, Tehran Institute of Psychiatry, Iran University of Medical Sciences, Tehran, Iran. ${ }^{6}$ Department of Psychology, Swansea University, Swansea, UK.
\end{abstract}

Received: 10 April 2021 Accepted: 7 September 2021

\section{Published online: 15 September 2021}

\section{References}

1. Ashburn SM, Flowers DL, Napoliello EM, Eden GF. Cerebellar function in children with and without dyslexia during single word processing. Hum Brain Mapp. 2020;41(1):120-38.

2. Schlaggar BL, McCandliss BD. Development of neural systems for reading. Annu Rev Neurosci. 2007;30:475-503.

3. Shaywitz SE, Shaywitz BA. Dyslexia (specific reading disability). Biol Psychiatry. 2005;57(11):1301-9.

4. Boyle CA, Boulet S, Schieve LA, Cohen RA, Blumberg SJ, Yeargin-Allsopp M, Visser S, Kogan MD. Trends in the prevalence of developmental disabilities in US children, 1997-2008. Pediatrics. 2011;127(6):1034-42.

5. Vellutino FR, Fletcher JM, Snowling MJ, Scanlon DM. Specific reading disability (dyslexia): what have we learned in the past four decades? J Child Psychol Psychiatry. 2004;45(1):2-40.

6. Snowling MJ. Phonemic deficits in developmental dyslexia. Psychol Res. 1981:43(2):219-34.

7. Ramus F, Rosen S, Dakin SC, Day BL, Castellote JM, White S, Frith U. Theories of developmental dyslexia: insights from a multiple case study of dyslexic adults. Brain. 2003;126(4):841-65.

8. Thomson JM, Richardson U, Goswami U. Phonological similarity neighborhoods and children's short-term memory: typical development and dyslexia. Mem Cognit. 2005;33(7):1210-9.

9. Beneventi $H$, Tonnessen FE, Ersland L, Hugdahl K. Working memory deficit in dyslexia: behavioral and FMRI evidence. Int J Neurosci. 2010:120(1):51-9.

10. Menghini D, Finzi A, Carlesimo GA, Vicari S. Working memory impairment in children with developmental dyslexia: is it just a phonological deficity? Dev Neuropsychol. 2011;36(2):199-213.

11. Baddeley A. Working memory: theories, models, and controversies. Annu Rev Psychol. 2012;63(1):1-29.

12. Ramus F, Rosen S, Dakin SC, Day BL, Castellote JM, White S, Frith U. Theories of developmental dyslexia: insights from a multiple case study of dyslexic adults. Brain. 2003;126(Pt 4):841-65.

13. Stein J. The magnocellular theory of developmental dyslexia. Dyslexia. $2001 ; 7(1): 12-36$

14. Ahissar M. Dyslexia and the anchoring-deficit hypothesis. Trends Cogn Sci. 2007;11(11):458-65.

15. Valdois S, Bosse ML, Tainturier MJ. The cognitive deficits responsible for developmental dyslexia: review of evidence for a selective visual attentional disorder. Dyslexia. 2004;10(4):339-63.

16. Nicolson RI, Fawcett AJ, Dean P. Developmental dyslexia: the cerebellar deficit hypothesis. Trends Neurosci. 2001;24(9):508-11.

17. Nicolson RI, Fawcett AJ. Developmental dyslexia, learning and the cerebellum. J Neural Transm Suppl. 2005;69:19-36.

18. Berninger WW, Raskind W, Richards T, Abbott R, Stock P. A multidisciplinary approach to understanding developmental dyslexia within working-memory architecture: genotypes, phenotypes, brain, and instruction. Dev Neuropsychol. 2008;33(6):707-44.

19. Gathercole SE, Alloway TP, Willis C, Adams AM. Working memory in children with reading disabilities. J Exp Child Psychol. 2006;93(3):265-81.

20. Wolf RC, Sambataro F, Lohr C, Steinbrink C, Martin C, Vasic N. Functional brain network abnormalities during verbal working memory performance in adolescents and young adults with dyslexia. Neuropsychologia. 2010;48(1):309-18.
21. Ravizza SM, McCormick CA, Schlerf JE, Justus T, Ivry RB, Fiez JA. Cerebellar damage produces selective deficits in verbal working memory. Brain. 2006:129(Pt 2):306-20.

22. Beneventi $H$, Tonnessen FE, Ersland L, Hugdahl K. Executive working memory processes in dyslexia: behavioral and fMRI evidence. Scand J Psychol. 2010;51(3):192-202.

23. Smith-Spark JH, Fisk JE. Working memory functioning in developmental dyslexia. Memory. 2007;15(1):34-56.

24. Luo Y, Wang J, Wu H, Zhu D, Zhang Y. Working-memory training improves developmental dyslexia in Chinese children. Neural Regen Res. 2013;8(5):452.

25. Loosli SV, Buschkuehl M, Perrig WJ, Jaeggi SM. Child neuropsychology: a journal on normal and abnormal development in childhood and adolescence. Child Neuropsychol. 2012;18(1):62-78.

26. Dahlin KIE. Effects of working memory training on reading in children with special needs. Read Writ. 2011;24(4):479-91.

27. Bucci MP, Bui-Quoc E, Gerard CL. The effect of a Stroop-like task on postural control in dyslexic children. PLoS ONE. 2013;8(10): e77920.

28. Goulème N, Gérard C-L, Bucci MP. The effect of training on postural control in dyslexic children. PLoS ONE. 2015;10(7): e0130196.

29. Gouleme N, Gerard CL, Bui-Quoc E, Bucci MP. Spatial and temporal analysis of postural control in dyslexic children. Clin Neurophysiol. 2015;126(7):1370-7.

30. Fawcett AJ, Nicolson RI, Dean P. Impaired performance of children with dyslexia on a range of cerebellar tasks. Ann Dyslexia. 1996;46(1):259-83.

31. Yap RL. Leij Avd: Testing the automatization deficit hypothesis of dyslexia via a dual-task paradigm. J Learn Disabil. 1994;27(10):660-5.

32. Marvel CL, Desmond JE. Functional topography of the cerebellum in verbal working memory. Neuropsychol Rev. 2010;20(3):271-9.

33. Bucci MP, Gerard CL, Bui-Quoc E. The effect of a cognitive task on the postural control of dyslexic children. Res Dev Disabil. 2013;34(11):3727-35.

34. Nicolson RI, Fawcett AJ. Development of dyslexia: the delayed neural commitment framework. Front Behav Nurosci. 2019;13:112.

35. Legrand A, Bui-Quoc E, Doré-Mazars K, Lemoine C, Gérard C-L, Bucci MP. Effect of a dual task on postural control in dyslexic children. PLOS ONE. 2012. https://doi.org/10.1371/journal.pone.0035301.

36. Wu T, Liu J, Hallett M, Zheng Z, Chan P. Cerebellum and integration of neural networks in dual-task processing. Neuroimage. 2013;65:466-75.

37. Pellecchia GL. Dual-task training reduces impact of cognitive task on postural sway. J Mot Behav. 2005;37(3):239-46.

38. Fritz NE, Cheek FM, Nichols-Larsen DS. Motor-cognitive dual-task training in persons with neurologic disorders: a systematic review. J Neurol Phys Ther. 2015;39(3):142-53.

39. Pichierri G, Murer K, de Bruin ED. A cognitive-motor intervention using a dance video game to enhance foot placement accuracy and gait under dual task conditions in older adults: a randomized controlled trial. BMC Geriatr. 2012;12(1):74.

40. Silsupadol P, Shumway-Cook A, Lugade V, van Donkelaar P, Chou L-S, Mayr U, Woollacott MH. Effects of single-task versus dual-task training on balance performance in older adults: a double-blind, randomized controlled trial. Arch Phys Med Rehab. 2009;90(3):381-7.

41. Kim GY, Han MR, Lee HG. Effect of dual-task rehabilitative training on cognitive and motor function of stroke patients. J Phys Ther. 2014:26(1):1-6.

42. Fernandes Â, Rocha N, Santos R, Tavares JMRS. Effects of dual-task training on balance and executive functions in Parkinson's disease: a pilot study. Somatosens Mot Res. 2015;32(2):122-7.

43. Melby-Lervag M, RedickTS, Hulme C. Working memory training does not improve performance on measures of intelligence or other measures of "far transfer": evidence from a meta-analytic review. Perspect Psychol Sci. 2016;11(4):512-34.

44. Karbach J, Strobach T, Schubert T. Adaptive working-memory training benefits reading, but not mathematics in middle childhood. Child Neuropsychol. 2015;21(3):285-301.

45. RedickTS, Shipstead Z, Wiemers EA, Melby-Lervag M, Hulme C. What's working in working memory training? An educational perspective. Educ Psychol Rev. 2015;27(4):617-33.

46. RedickTS. Working memory training and interpreting interactions in intelligence interventions. Intelligence. 2015;50:14-20. 
47. Melby-Lervag M, Hulme C. There is no convincing evidence that working memory training is effective: a reply to Au et al. (2014) and Karbach and Verhaeghen (2014). Psychon Bull Rev. 2016;23(1):324-30.

48. Melby-Lervag M, Hulme C. Is working memory training effective? A meta-analytic review. Dev Psychol. 2013;49(2):270-91.

49. Klingberg T. Training and plasticity of working memory. Trends Cogn Sci. 2010;14(7):317-24

50. Shipstead Z, Hicks KL, Engle RW. Cogmed working memory training: does the evidence support the claims? JARMAC. 2012;1(3):185-93.

51. Moradi AHM, Kormi Nouri R, Hassani J, Parhoon H. Reliability and validity of reading and dyslexia test (NEMA). Advan Cogn Sci. 2016;18(1):22-34

52. Duncan LG, Johnston RS. How does phonological awareness relate to nonword reading skill amongst poor readers? Read Writ. 1999;11(5):405-39.

53. Members P. Resolution of the seven hundred and seventy session of the Higher Education Council [Translated]. Official site of the Islamic Parliament Research Center of the Islamic Republic of IRAN. 2008.

54. Rostami R, Sadeghi V, Zarei J, Haddadi P, Mohazzab-Torabi S, Salamati P. Concurrent validity of Persian version of Wechsler intelligence scale for children-and cognitive assessment system in patients with learning disorder. Iran J Pediatr. 2013;23(2):183.

55. Mohammad Esmaeel E. Adaptation and standardization of child symptom inventory-4 (CSI-4). Except Child. 2007;7(1):79-96.

56. Sprafkin J, Volpe RJ, Gadow KD, Nolan EE, Kelly K. A DSM-IV-referenced screening instrument for preschool children: the early childhood inventory-4. J Am Acad Child Adolesc Psychiatry. 2002;41(5):604-12.

57. Achenbach TM. Manual for the child behavior checklist/4-18 and 1991 profile. Vermont: University of Vermont, Department of Psychiatry; 1991

58. Schulz KF, Altman DG, Moher D. CONSORT 2010 statement: updated guidelines for reporting parallel group randomised trials. BMC Med. 2010;8:18.

59. Heinzel S, Schulte S, Onken J, Duong QL, Riemer TG, Heinz A, Kathmann $\mathrm{N}$, Rapp MA. Working memory training improvements and gains in non-trained cognitive tasks in young and older adults. Neuropsychol Dev Cogn B Aging Neuropsychol Cogn. 2014;21(2):146-73.

60. Thorell LB, Lindqvist S, Bergman Nutley S, Bohlin G, Klingberg T. Training and transfer effects of executive functions in preschool children. Dev sci. 2009;12(1):106-13.

61. Pugin F, Metz A, Stauffer M, Wolf M, Jenni O, Huber R. Working memory training shows immediate and long-term effects on cognitive performance in children [version 3; peer review: 2 approved]. F1000Res. 2015. https://doi.org/10.12688/f1000research.3665.3.

62. Julious S. The size of a pilot study for a clinical trial should be calculated in relation to considerations of precision and efficiency. Pharm Stat. 2005;4:287-91.

63. Kim J, Shin W. How to do random allocation (randomization). Clin Orthop Surg. 2014;6(1):103-9.

64. Shokouhi S, Abdolahi E, Behzadipour S. Validity of a customized balance board for assessment of static and dynamic balance. In: 27th annual conference of mechanical engineering. Iranian Sociaty of Mechanical Engineers. 2019.

65. Pourghayoomi E, Behzadipour S, Ramezani M, Joghataei MT, Shahidi GA. A new postural stability-indicator to predict the level of fear of falling in Parkinson's disease patients. Biomed Eng Online. 2020;19(1):64.

66. Woods DL, Kishiyamaa MM, Lund EW, Herron TJ, Edwards B, Poliva O, Hink RF, Reed B. Improving digit span assessment of short-term verbal memory. J Clin Exp Neuropsychol. 2011;33(1):101-11.

67. Orangi M, Atefvahid MK, Ashayeri H. Standardization of the Revised Wechsler memory scale in Shiraz. IJPCP. 2002;7(4):56-66.

68. Homack S, Riccio CA. A meta-analysis of the sensitivity and specificity of the Stroop color and word test with children. Arch Clin Nuropsych. 2004;19(6):725-43.

69. Lazarus PJ, Ludwig RP, Aberson B. Stroop color-word test: a screening measure of selective attention to differentiate LD from non LD children. J Educ Psychol. 1984;21(1):53-60.

70. Golden ZL, Golden CJ. Patterns of performance on the Stroop color and word test in children with learning, attentional, and psychiatric disabilities. J Sch Psychol. 2002;39(5):489-95.
71. Lezak MD, Howieson DB, Loring DW, Fischer JS. Neuropsychological assessment. Oxford: Oxford University Press; 2004.

72. Pourghayoomi E, Negahdar F, Shahidi G, Hassani Mehraban A, Ebrahimi I, Taghizade G, Mirshoja M, Saeidi Boroujeni M. Correlation between functional balance and mobility tests and postural sway measures in dual task paradigm in Parkinson's disease (a pilot study). JBCPP. 2014;2(2):1-12.

73. Loras H, Sigmundsson H, Stensdotter A-K, Talcott JB. Postural control is not systematically related to reading skills: implications for the assessment of balance as a risk factor for developmental dyslexia. PloS ONE. 2014;9(6):e98224-e98224.

74. Pozzo T, Vernet P, Creuzot-Garcher C, Robichon F, Bron A, Quercia P. Static postural control in children with developmental dyslexia. Neurosci Lett. 2006;403(3):211-5.

75. Polskaia N, Lajoie Y. Reducing postural sway by concurrently performing challenging cognitive tasks. Hum Mov Sci. 2016;46:177-83.

76. Pia Bucci M, Bui-Quoc E, Gerard C-L. The effect of a Stroop-like task on postural control in dyslexic children. PLoS ONE. 2013;8(10): e77920.

77. Gouglidis V, Nikodelis T, Hatzitaki V, Amiridis IG. Changes in the limits of stability induced by weight-shifting training in elderly women. Exp Aging Res. 2011;37(1):46-62.

78. Ghasemi A, ZahediasI S. Normality tests for statistical analysis: a guide for non-statisticians. Int J Endocrinol Metab. 2012;10(2):486-9.

79. Field A. Discovering statistics using IBM SPSS statistics. New York: Sage; 2013.

80. Lakens D. Calculating and reporting effect sizes to facilitate cumulative science: a practical primer for t-tests and ANOVAs. Front Psychol. 2013;4:863-863.

81. Richardson JT. Eta squared and partial eta squared as measures of effect size in educational research. Educ Res Rev. 2011;6(2):135-47.

82. Shatil E. Does combined cognitive training and physical activity training enhance cognitive abilities more than either alone? A four-condition randomized controlled trial among healthy older adults. Front Aging Neurosci. 2013;5: 8 .

83. Laatar R, Kachouri H, Borji R, Rebai H, Sahli S. Combined physical-cognitive training enhances postural performances during daily life tasks in older adults. Exp Gerontol. 2018;107:91-7.

84. Schmidt M, Mavilidi MF, Singh A, Englert C. Combining physical and cognitive training to improve kindergarten children's executive functions: a cluster randomized controlled trial. Contemp Educ Psychol. 2020;63: 101908.

85. Fraizer EV, Mitra S. Methodological and interpretive issues in posturecognition dual-tasking in upright stance. Gait Posture. 2008;27(2):271-9.

86. Veltman DJ, Rombouts SARB, Dolan RJ. Maintenance versus manipulation in verbal working memory revisited: an fMRI study. Neuroimage. 2003;18(2):247-56.

87. Nicolson RI, Fawcett AJ. Procedural learning, dyslexia and delayed neural commitment. In: Lachmann T, Weis T, editors. Reading and dyslexia. Springer: Berlin; 2018. p. 235-69.

88. Barela JA, Dias JL, Godoi D, Viana AR, de Freitas PB. Postural control and automaticity in dyslexic children: the relationship between visual information and body sway. Res Dev Disabil. 2011;32(5):1814-21.

89. Huxhold O, Li S-C, Schmiedek F, Lindenberger U. Dual-tasking postural control: aging and the effects of cognitive demand in conjunction with focus of attention. Brain Res Bull. 2006;69(3):294-305.

90. Polskaia N, Richer N, Dionne E, Lajoie Y. Continuous cognitive task promotes greater postural stability than an internal or external focus of attention. Gait Posture. 2015;41(2):454-8.

91. Isableu B, Hlavackova P, Diot B, Vuillerme N. Regularity of center of pressure trajectories in expert gymnasts during bipedal closed-eyes quiet standing. Front Hum Neurosci. 2017;11:317.

92. Rochelle KS, Talcott JB. Impaired balance in developmental dyslexia? A meta-analysis of the contending evidence. J Child Psychol Psychiatry. 2006:47(11):1159-66.

93. Stoodley CJ, Stein JF. Cerebellar function in developmental dyslexia. Cerebellum. 2013;12(2):267-76.

94. Loras H, Sigmundsson H, Stensdotter A-K, Talcott JB. Postural control is not systematically related to reading skills: implications for the 
assessment of balance as a risk factor for developmental dyslexia. PLoS ONE. 2014;9(6): e98224.

95. Wang S, Gathercole SE. Working memory deficits in children with reading difficulties: memory span and dual task coordination. J Exp Child Psychol. 2013;115(1):188-97.

96. Knoop-van Campen CAN, Segers E, Verhoeven L. How phonological awareness mediates the relation between working memory and word reading efficiency in children with dyslexia. Dyslexia. 2018;24(2):156-69.

97. Rispens J, Baker A. Nonword repetition: the relative contributions of phonological short-term memory and phonological representations in children with language and reading impairment. J Speech Lang Hear. 2012;55(3):683-94.

98. Tong X, Deacon SH, Kirby JR, Cain K, Parrila R. Morphological awareness: a key to understanding poor reading comprehension in English. J Educ Psychol. 2011;103(3):523-34.

99. Soutschek A, Strobach T, Schubert T. Working memory demands modulate cognitive control in the Stroop paradigm. Psychol Res. 2013;77(3):333-47.

100. Kalanthroff E, Avnit A, Henik A, Davelaar EJ, Usher M. Stroop proactive control and task conflict are modulated by concurrent working memory load. Psychon Bull Rev. 2015;22(3):869-75.

101. Fujita H, Kasubuchi K, Osumi M, Morioka S. Effects of the central executive on postural control. J Mot Behav. 2016;48(3):270-6.

102. Oberauer K. Working memory and attention - a conceptual analysis and review. J Cogn. 2019. https://doi.org/10.5334/joc.58.

103. Nicolson RI, Fawcett AJ. Procedural learning difficulties: reuniting the developmental disorders? Trends Neurosci. 2007;30(4):135-41.

104. Nicolson RI, Fawcett A, Brookes R, Needle J. Procedural learning and dyslexia. Dyslexia. 2010;16(3):194-212.

105. Schlerf JE, Verstynen TD, IVry RB, Spencer RMC. Evidence of a novel somatopic map in the human neocerebellum during complex actions. J Neurophysiol. 2010;103(6):3330-6.
106. Marien P, Ackermann H, Adamaszek M, Barwood CH, Beaton A, Desmond J, De Witte E, Fawcett AJ, Hertrich I, Kuper M, et al. Consensus paper: language and the cerebellum: an ongoing enigma. Cerebellum. 2014;13(3):386-410.

107. Chen SH, Desmond JE. Cerebrocerebellar networks during articulatory rehearsal and verbal working memory tasks. Neuroimage. 2005;24(2):332-8.

108. Stoodley CJ. The cerebellum and cognition: evidence from functional imaging studies. Cerebellum. 2012;11(2):352-65.

109. Carreiras M, Mechelli A, Estevez A, Price CJ. Brain activation for lexical decision and reading aloud: two sides of the same coin? I Cogn Neurosci. 2007;19(3):433-44.

110. Reynolds D, Nicolson Rl, Hambly H. Evaluation of an exercisebased treatment for children with reading difficulties. Dyslexia. 2003;9(1):48-71.

111. Rack JP, Snowling MJ, Hulme C, Gibbs S. No evidence that an exercisebased treatment programme (DDAT) has specific benefits for children with reading difficulties. Dyslexia. 2007;13(2):97-104.

112. Al-Wabil A, Zaphiris P, Wilson S. Examining visual attention of dyslexics on web navigation structures with eye tracking. In: 2008 international conference on innovations in information technology: 2008: IEEE; 2008. p. 717-21.

113. Skottun BC, Skoyles JR. Attention, reading and dyslexia. Clin Exp Optom. 2006;89(4):241-5.

\section{Publisher's Note}

Springer Nature remains neutral with regard to jurisdictional claims in published maps and institutional affiliations.
Ready to submit your research? Choose BMC and benefit from:

- fast, convenient online submission

- thorough peer review by experienced researchers in your field

- rapid publication on acceptance

- support for research data, including large and complex data types

- gold Open Access which fosters wider collaboration and increased citations

- maximum visibility for your research: over $100 \mathrm{M}$ website views per year

At BMC, research is always in progress.

Learn more biomedcentral.com/submissions 